\title{
Antioxidants for clinical use
}

\author{
K. M. Prasanna Kumar
}

Received: 5 September 2012 / Accepted: 12 September 2012 /Published online: 19 October 2012

(C) Research Society for Study of Diabetes in India 2012

Free radicals are molecules, which lack an electron in their chemical structure, which they constantly try to replace. The free radicals try to get electrons from the body, which causes "oxidative stress," which in turn results in damage to the body's cells and tissues. Antioxidants provide the extra electrons to the free radicals and prevent them from causing damage to the body's cells and tissues. Since world war II the free radicals biochemistry came into vogue. Free radicals have been implicated in the etiology of several human diseases as well as ageing $[1,2]$.

Halliwell \& Gutteridge (1989) [3] state that an antioxidant is "any substance that, when present at low concentrations compared with that of an oxidizable substrate, significantly delays or inhibits oxidation of that substrate". This definition includes reactions of a non-enzymatic as well as an enzymatic nature. There are many protective antioxidant mechanisms like- superoxide dismutase, catalase, glutathione, glutathione peroxidase, reductase and non-enzymatic antioxidants like carotenoids, flavonoids, trace elements like zinc,selenium, probucol, vitamins like vitamin $\mathrm{E}$ and vitamin $\mathrm{C}$ (ascorbic acid), which are available in nature. Fruits, vegetables, minerals, tea and nuts are good source of anti-oxidants.

Free radicals by lipid peroxidation adversely affect lipids, proteins and DNA. Free radical can damage the proteins, which results in the loss of enzyme activity. Damage caused to DNA, can result in mutagenesis and carcinogenesis [4].Antioxidants like phenols,flavonoids, isoflavones, isothiocyanates, diterpenes, methylxanthines, dithiols, and coumarins appear to be important in cancer prevention [5].

The epidemiological studies showed that higher intake of foods with antioxidant can prevent and control certain diseases in humans. Many natural products and Indian spices and ayurvedic products are known to possess antioxidant

K. M. P. Kumar $(\bowtie)$

Endocrinology, Metabolism \& Diabetes- MS Ramaiah Medical

College, CEO- Bangalore Diabetes hospital,

Bangalore, India

e-mail: dr.kmpk@gmail.com activity. Many epidemiological studies have shown association between consumption of vitamins and anti oxidants and reduction in cardiovascular diseases and its morbidity and mortality. These are mostly observational studies.

An article by Shital S Panchal on Anti-diabetic activity of oryzanol and its relationship with the anti-oxidant property, in this issue [6] showed that oryzanol (OZ), a commerciallyimportant bioactive phytochemical isolated from crude rice bran oil (cRBO), possesses the potential to effectively ameliorate the oxidative stress in diabetic rats. Translating the knowledge and experiments from bench to bedside is not an easy task.

There are many publications on the role of antioxidants and their efficacy in preventing or curing metabolic disorders like diabetes mellitus, inflammatory diseases like periodontitis, aging diseases like ischaemic heart diseases, cancer and degenerative diseases like Alzeimers disease, Parkinsonism. There are very few RCT's in human beings to prove the efficacy of antioxidants in prevention, control or cure of chronic diseases. One of the clinical studies with probucol an antioxidant, in 317 patients showed probucol, is effective in reducing the rate of restenosis after balloon coronary angioplasty [7].

A literature search of pubmed by Saeid Golbidi,et al. [8] for effect of antioxidants like vitamin E, vitamin C, CoQ10, alpha lipoic acid, L-carnitine, ruboxistaurin or LY 333531 in diabetes mellitus, revealed that routine vitamin or mineral supplementation is not generally recommended in human diabetes.

Tocopherol and Coenzyme Q10 have been tried in prevention and treatment of Parkinson's disease with limited success. A review of antioxidants in Parkinson's disease [9] concluded that antioxidants have limited role in the prevention and treatment. They are also of the opinion that CoQ10 has some minor benefits in Parkinson disease.

Though there is plenty of literature on the role of antioxidants in etiopathogenesis of disease in human beings, is the evidence enough to use antioxidants in clinical practice to prevent,control and "cure" diseases and reduce the mortality and morbidity? Another issue is dose of antioxidants and use of combination therapy. Translating the dose of 
antioxidants to human trials is not an easy issue. Each study has used different doses of antioxidant. Is there a dose-effect relationship between the dose of antioxidant for prevent, control and cure of disease? Does one size fit all? Is the combination of two or more anti oxidants better than the summed benefits of each antioxidant. There is no simple answer for these questions in evidence based medicine. We need to wait for larger and longer studies in human beings on the effect of antioxidants in preventing disease, promoting health and reducing morbidity and mortality of acute and chronic illnesses.

Future research like gene therapy to enhance production of antioxidants in the human body, genetically engineered plant products with higher concentrations of antioxidants, synthetic antioxidant enzymes or non enzymatic chemical molecules,newer peptides with antioxidant properties developed by recombinant DNA technology and computational chemistry and functional foods enriched with antioxidants will replace the present anti-oxidant remedies.

\section{References}

1. Harman D. Ageing: a theory based on free radical and radiation chemistry. J Gerontol. 1956;11:298-300.

2. Halliwell B, Gutteridge JMC, editors. Free radicals in biology and medicine. Oxford: Oxford University Press; 1997.

3. Halliwell B, Gutreridge JMC. Free radicals in biology and medicine. 2nd ed. Oxford: Clarendon Press; 1989.

4. Devasagayam TPA, Tilak JC, Boloor KK, Sane KS, Ghaskadbi SS, Lele RD. Free radicals and antioxidants in human health: current status and future prospects. JAPI. 2004;52:794-804.

5. Krishnaswami K. Indian functional food: role in prevention of cancer. Nutr Rev. 1996;54:S127-31.

6. Panchal SS. Anti-diabetic activity of oryzanol and its relationship with the anti-oxidant property. Int J Diab Dev Ctries. doi:10.1007/ s13410-012-0086-y.

7. Claude J, Gillescôté T, Espérance J, Ourassa MB, Ambert J, Oucet SD, et al. N Engl J Med 1997;337:365-72.

8. Golbidi S, Ebadi SA, Laher I. Antioxidants in the treatment of diabetes. Curr Diabetes Rev. 2011;7:106-25.

9. Weber AC, Ernst ME. Drug information rounds-antioxidants, supplements and parkinson's disease. Ann Pharmacother. 2006;40:935-8. 